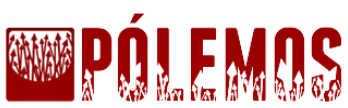

\section{O PAPEL DA VONTADE NA CONSTITUIÇÃO DO ERRO NA QUARTA MEDITAÇÃO DE DESCARTES}

\author{
Diôgo Costa Fernandes
}

Graduado em Filosofia pela Faculdade Jesuíta de Filosofia e Teologia (FAJE)

\section{RESUMO}

O filósofo René Descartes (1596-1650) em seus escritos sobre as Meditações sobre a Filosofia Primeira, especificamente na Quarta Meditação, aborda a problemática do erro diante dos juízos emitidos pelo homem. Esse tema foi de grande importância para autor, pois com esses escritos ele almejava alcançar bases sólidas para o edifício do conhecimento científico. No afã de descobrir as causas do erro a fim de evitá-las, Descartes sugere uma estreita relação entre o erro e a vontade, situando o mau uso do livre-arbítrio como fonte dos falsos juízos. Este artigo pretende apresentar a relação entre a vontade e o erro, definindo a compreensão cartesiana dos mesmos, bem como mostrar o papel de Deus nessa relação e qual é um possível caminho para se evitar o juízo errôneo.

Palavras-chave: Descartes; erro; vontade; juízo.

\begin{abstract}
The philosopher René Descartes (1596-1650) in his text about Meditation on First Philosophy, specifically on Fourth Meditation, deals with the problem of the error up against the human being judgments. This issue was very important to the author, because with this text he would reach solid bases to the cientific knowledge. In an effort to discover the causes of the error in order to avoid them, Descartes suggests a close relationship between the error and the will, showing the bad use of the free will as the source of the false judgments. This article wants to introduce the relationship between will and error, defining the cartesian understanding of them, showing the role of God in this relationship and what is a possible way to avoid a misjudgment.
\end{abstract}

Keywords: Descartes; error, will, judgment.

Ao apresentar a proposta das Meditações sobre a Filosofia Primeira, Descartes tem como objetivo principal a busca de fundamentos sólidos para a construção do conhecimento, neste caso, o conhecimento das ciências $^{1}$. Tal conhecimento se destaca pela superação da

\footnotetext{
${ }^{1}$ Este empreendimento de uma nova formulação para as Ciências Naturais pode ser encontrado logo no primeiro parágrafo da primeira meditação. Essa busca por fundamentos sólidos aponta para um progressivo abandono da filosofia Escolástica do tempo de Descartes e a proposta de uma nova Filosofia Natural que é construída ao longo das meditações. DESCARTES, 1988, p.105. Cottingham introduz bem esse tema quando apresenta o contexto histórico de Descartes, assim como as transformações no campo da Ciência daquele tempo e as relações dele com a Escolástica. Vale destacar o processo histórico comumente chamado de Revolução Científica, em que outros grandes expoentes, como Galileu e Kepler, buscavam novo modo de se conhecer o mundo. Eles, juntamente a Descartes, apostaram na Matemática como chave para compreensão dos fundamentos da realidade. Sendo assim, esse termo conhecimento das ciências não se refere à Ciência tal como podemos conceber hoje, como um conjunto de prescrições convencionais que servem para testar determinada teoria. Mas as bases para o que hoje chamamos de ciência foram aí lançadas. O objetivo de Descartes era encontrar precisão e solidez para o conhecimento, visto sua decepção com os convencionais resultados obtidos pela filosofia Escolástica.
} 
Filosofia Escolástica, principalmente pela consideração de que o conteúdo não se fundamenta mais nos dados fornecidos pelos sentidos, e pelo próprio critério de verificação do conhecimento $^{2}$, que agora se vincula e serve de base para as Ciências Naturais. Após traçar um longo caminho meditativo ${ }^{3}$ e encontrar a certeza do $\operatorname{cogito}^{4}$, Descartes formula as provas da existência de Deus, demonstrando que esse Deus é sumamente bom e não pode ser enganador. A ideia de Deus assumida por Descartes não permite a contradição entre um ser todo poderoso, sumamente bom e a capacidade de errar, o que seria um sinal de imperfeição. Contudo, ao se voltar para a realidade da vida humana cotidiana, o autor nota que muitas vezes são emitidos juízos errôneos sobre as coisas, ao que ele se coloca a questão: se Deus não pode ser enganador e visto que somos criados por Deus, por que erramos? Este trabalho tem por objetivo apresentar o papel da vontade na constituição do erro na Quarta Meditação, mostrando que o erro é fruto do mau uso do livre arbítrio, em outras palavras, que ele é oriundo do mau uso da vontade. Também será apresentada a solução cartesiana para o problema da emissão de juízos errôneos. Para tanto, buscaremos distinguir as faculdades da vontade e do entendimento para Descartes, expor sua teoria do erro bem como uma proposta de solução ao problema do erro. Para concluir, inferiremos um critério de verificação da verdade que surge a partir da teoria do erro.

No contexto do argumento da prova da existência de Deus, presente na Terceira

(COTTINGHAN, 1989, pp.13-38).

${ }^{2}$ Descartes recebeu sua formação inicial com base na Escolástica, principalmente a ensinada pelos jesuítas no colégio de La Flèche. Ela é o que caracteriza e Filosofia clássica Medieval, baseando-se, principalmente na filosofia de Aristóteles e nas interpretações que Tomás de Aquino deu a tal filosofia (COTTINGHAN, 1989, pp.17-22). Após anos de aprendizado, ele começa a desconfiar dos ensinamentos recebidos em sua infância, decidindo-se pela busca de um fundamento sólido para o conhecimento. Para a relação de Descartes com a Escolástica e com os jesuítas, ver: ARIEW, Roger. Descartes e o escolasticismo: o pano de fundo intelectual do pensamento de Descartes. In: COTTINGHAM, John. [Org.] Descartes. Aparecida: Ideias \& Letras, 2009. (Coleção Companions \& Companions).

${ }^{3}$ O gênero literário elegido por Descartes é de significativa importância para o desenvolvimento do texto das Meditações. O autor convida o leitor a não apenas fazer uma leitura de seus escritos, mas deter-se nos textos de modo a meditá-los. Esse gênero meditativo era muito comum no período de Descartes, principalmente pela formação e relação que ele teve com os jesuítas. Estes, guiados pelos escritos do fundador da Companhia de Jesus, Inácio de Loyola, aplicaram as intuições do fundador referentes à espiritualidade dos jesuítas no método de ensino, surgindo, assim, o documento da Ratio Studiorum (séc. XVI) que apresentava as diretrizes da educação jesuítica. Grande parte da inspiração do gênero meditativo pode ser encontrada em: LOYOLA, Inácio de. Exercícios Espirituais. 3.ed. São Paulo: Edições Loyola, 2006.

${ }^{4}$ Descartes, na Primeira Meditação, coloca em questão o conhecimento humano. Ele traça um caminho que, primeiramente, lança dúvidas sobre o conhecimento proveniente dos sentidos, da Matemática e até mesmo de Deus. Com a hipótese do gênio maligno, uma hipótese metodológica que visa a superação do apego aos dados da experiência sensível, o autor chega a assumir como falso tudo que se apresenta como duvidoso. Na Segunda Meditação, Descartes retoma a reflexão da meditação anterior e chega à afirmação do cogito com o seguinte pensamento: "De maneira que, depois de ter pesado e repesado muito bem tudo isto, deve por último concluir-se que esta proposição Eu sou, eu existo, sempre que proferida por mim ou concebida pelo espírito, é necessariamente verdadeira." (DESCARTES, 1998, p.119). 
Meditação, Descartes apresenta uma distinção no modo de compreender uma ideia ${ }^{5}$. Esta pode ser compreendida por sua realidade formal, enquanto um modo de pensar, como atos psíquicos. Pensadas dessa forma, as ideias são todas iguais, pois se resumem a atos de pensamento e não cabe a elas um juízo de verdade ou falsidade ${ }^{6}$. Mas a ideia também pode ser compreendida por sua realidade objetiva. Nesse caso, toma-se como referência seu conteúdo representativo $^{7}$. As ideias de homem e de Deus são iguais se tomadas em sua realidade formal, mas são diferentes se analisadas em sua realidade objetiva. Essa reflexão cartesiana se faz pertinente quanto ele busca a origem, a causa dessas ideias. Ao se colocar a questão sobre a causa de uma ideia, o autor pontua que o efeito deve retirar sua realidade da causa. Mais ainda: “[...] que deve haver pelo menos tanta realidade objetiva na causa eficiente e total como no efeito da mesma causa." (DESCARTES, 1988, p. 145). Disso se conclui, também, que algo não pode surgir do nada ${ }^{8}$. Com isso, a própria ideia do cogito deve ter uma causa que possua, ao menos, tanta realidade quanto ela. Descartes também rejeita o pensamento de uma progressão das causas ao infinito e, assim, afirma a necessidade de uma causa primeira ${ }^{9}$. Se pensarmos em termos de ideias, pensamos em uma ideia que seja direta ou indiretamente a causa de todas outras ideias.

Ainda nessa linha de reflexão, Descartes se volta para a ideia de Deus e a descreve como "[...] uma certa substância infinita, independente, sumamente inteligente, omnipotente, e pela qual foram criados quer eu mesmo, quer tudo o resto que existe, se é que alguma coisa existe." (Ibid, p.151-152). Seguindo o princípio de causalidade, a causa dessa ideia de Deus deve ter ao menos tanta realidade objetiva quanto a própria ideia a que se refere, o que significa que deve existir um ser que seja causa dessa ideia, ou seja, o próprio Deus. Além do mais, o autor ainda afirma que uma substância finita não pode ser causa de uma substância infinita, o que mostra a necessidade causal de Deus, pois o ser humano em sua limitação e finitude não poderia criar tal ideia ${ }^{10}$. Outra característica de Deus que é apresentada é a sua perfeição, que está vinculada à sua infinitude ${ }^{11}$. Não há nada que poderia ser acrescentado a Deus, pois a incompletude seria sinal de imperfeição e não assumiria a ideia de Deus como

\footnotetext{
${ }^{5}$ Descartes apresenta a ideia como um produto do pensamento, aquilo que é percebido pelo espírito. Nesse caso, são expressões dessa natureza a ideia de homem, de cachorro, mas também quando se teme, quando se deseja (DESCARTES, 1988, p.139). ${ }^{6}$ DESCARTES, 1988, p.140.

${ }^{7}$ Ibid, p.144.

${ }^{8}$ DESCARTES, 1988, p.145.

${ }^{9}$ Ibid, p.147.

${ }^{10}$ Ibid, p.152.

${ }^{11}$ Ibid, p.155-156.
} 
causa primeira.

Propriamente no terreno da Quarta Meditação, Descartes retoma o tema da impossibilidade de Deus ser enganador, o que foi brevemente concluído na meditação anterior. O pensamento básico é que Deus não pode ser enganador, pois o engano é sinal de imperfeição. Vale acrescentar que o autor se volta para o aparente paradoxo entre o fato de Deus não ser enganador e o ser humano ter sido criado por ele e estar sujeito ao erro. O desejo e ato de enganar revela-se uma "fraqueza de espírito", o que não pode pertencer a Deus ${ }^{12}$. Além disso, se a dúvida hiperbólica ${ }^{13}$, que possibilitou a reflexão sobre o Deus enganador, persistisse, seria difícil chegar ao conhecimento claro $e$ distinto ${ }^{14}$ de outra ideia senão a do cogito, o que entraria em contradição com a prova da existência de Deus ${ }^{15}$. Por isso não se pode perder de vista o caráter metodológico da dúvida, pois o objetivo cartesiano não é permanecer na dúvida, mas, ao contrário, chegar ao conhecimento claro e distinto. Também o erro é sinal de imperfeição. É nesse contexto que se justifica a reflexão cartesiana sobre o erro, pois ele parte da análise de que muitas vezes erramos. Se erramos, esse erro não pode vir de Deus. O ser humano também não foi criado com uma faculdade de errar, caso contrário, revelar-se-ia uma contradição em Deus, visto que o erro é um mal e não é próprio de um ser perfeito.

Ao pensar a ideia de Deus como um ente sumamente perfeito, Descartes também pensa, de modo negativo, a ideia de nada, ou seja, um total afastamento de toda perfeição. Ele situa o homem entre essas duas ideias, na medida em que ao homem faltam muitas das perfeições que se encontram em Deus. Poderíamos dizer que a ideia de nada não possui uma

\footnotetext{
${ }^{12}$ Ibid, p.166.

${ }^{13} \mathrm{Na}$ Primeira Meditação, Descartes iniciou o método da dúvida ao colocar o conhecimento proveniente dos sentidos como duvidoso. Após isso, ele também coloca em dúvida, pelo argumento do Deus enganador, as evidências da Matemática. Ele eleva a dúvida ao extremo quando supõe, ao invés de um Deus enganador, a figura de um gênio maligno, que teria como objetivo sempre enganar o ser humano. Em consequência desse exagero, Descartes toma a resolução de assumir como falso tudo aquilo que é duvidoso. Esse exagero no método da dúvida caracteriza a dúvida hiperbólica. Forlin, ao escrever sobre a dúvida hiperbólica, diz que ela tem pretensões à universalidade, pois coloca em questão os dados dos sentidos (dúvida natural) e a própria validade da experiência (dúvida metafísica). Ver: FORLIN, 2004, p.17-24.

${ }^{14}$ Descartes considera que o conhecimento humano, para que seja seguro, deve se apoiar em um conhecimento claro e distinto da realidade. Por tal conhecimento, o autor considera todas as proposições que são evidentes por si mesmas e suportam quaisquer dúvidas que poderiam ser lançadas sobre elas. Também é característica do conhecimento claro e distinto a simplicidade, pois ele trata das coisas mais elementares. Sendo assim, quando o ser humano se depara com uma ideia clara e distinta, ela não pode ser assumida como falsa ou enganosa. No que se refere à percepção clara e distinta, Descartes nos escreve, nos Princípios da Filosofia: "Chamo de clara àquela que está presente e manifestante a um espírito atento: da mesma maneira que dizemos ver claramente os objetos que, quando presentes, atuam suficientemente forte e que nossos olhos estão dispostos a olhá-los. E distinto, àquela que é tão precisa e diferente de todas as outras, que integra em si só o que parece com clareza a quem, razoavelmente, a considera." (Id, 1970, p.84 - tradução nossa).

${ }^{15}$ TEIXEIRA, 1990, p.51.
} 
realidade objetiva, ela é apenas privação de toda perfeição da ideia de Deus ${ }^{16}$. Com isso, o erro encontra sua legitimação na privação da perfeição divina. $\mathrm{O}$ autor, então, delimita o campo do erro aos seres que não possuem a perfeição de Deus e, ao mesmo tempo, não fundamenta o erro no próprio Deus. Como a ideia de nada é pensada como uma negatividade no sentido de privação, não encontramos uma realidade objetiva para o erro. Todavia, Descartes não se mostrou satisfeito apenas em demonstrar que o erro não provém de Deus e que o ser humano não é criado com uma faculdade de errar. Cabe, agora, perguntar-se como o ser humano erra, a fim de compreender melhor o próprio erro.

Há, segundo o autor, duas causas ou motivos que concorrem para o erro: a faculdade de conhecer, ou entendimento e a faculdade de eleger, ou vontade ${ }^{17}$. Vale lembrar que uma ideia, enquanto realidade formal, não é verdadeira ou falsa, pois a ela não cabe algum tipo de juízo. O problema do erro surge quando o ser humano afirma ou nega algo sobre a realidade objetiva de uma ideia ${ }^{18}$. Ethel Menezes, ao falar dessas duas faculdades do espírito humano, diz-nos que a vontade é uma faculdade ativa, voltada para a ação intelectual. Ela também se refere ao conjunto de volições de um indivíduo. Por outro lado, acrescenta Menezes, o entendimento é uma faculdade passiva, que se destina ao conhecimento das ideias em que a vontade opera. Essas duas faculdades estão em estreita ligação, pois a vontade só opera quando tem diante de si algum conteúdo proveniente do entendimento. Caso não haja esse conteúdo do entendimento, a vontade não é excitada a agir ${ }^{19}$.

É interessante notar que essas duas faculdades encontram uma unidade no próprio cogito. Após chegar à ideia clara e distinta do eu penso, eu existo, Descartes se pergunta sobre o que é sua existência, chegando à conclusão de que é uma coisa pensante ${ }^{20}$. Esta, por sua vez, apresenta várias características, tais como o entender e o querer. Por mais que a res cogitans tenha sua essência no ato de pensar, este ato se desdobra no entendimento e na vontade, como

\footnotetext{
${ }^{16}$ DESCARTES, 1988, p.167.

${ }^{17}$ Ibid, p. 170 .

${ }^{18} \mathrm{Na}$ Terceira Meditação, quando Descartes faz uma distinção dos pensamentos e das ideias, ele afirma que as ideias e os afetos não são verdadeiros nem falsos. Ocorre verdade e falsidade apenas nos juízos. Ainda sobre os juízos, ele escreve: "Ora, o erro principal e mais frequente que se pode descobrir neles consiste em que afirmo que as ideias que estão em mim são semelhantes ou conformes a certas coisas que estão fora de mim. Porque, na verdade, se considerasse as próprias ideias apenas como certos modos do meu pensamento e não as referisse a qualquer outra coisa, dificilmente me poderiam me oferecer matéria de erro." (DESCARTES, 1988, p.140). Sobre as distinções do pensamento e das ideias ver: DESCARTES, 1988, p. 139-144.

${ }^{19}$ MENEZES, 2011, p.129.

${ }^{20}$ Descartes escreve: "Mas que sou eu então? Uma coisa pensante. O que isso quer dizer? Quer dizer: uma coisa que duvida, que compreende, que afirma, que nega, que quer, que não quer, que também imagina, e que sente." (Id, 1988, p.124).
} 
funções distintas $^{21}$. Além da distinção entre essas funções, há a ideia de que elas possuem uma abrangência diferenciada. $O$ entendimento no ser humano possui a característica de ser limitado, pois o homem não tem posse de todas as ideias claras e distintas. Essa perfeição é atribuída apenas a Deus. Porém, no que diz respeito à vontade, esta possui uma dimensão ilimitada. Descartes, por não conseguir conceber uma vontade maior do que a ser humano, afirma que essa ilimitação da vontade é como que uma marca de que o homem é criado à imagem e semelhança de Deus ${ }^{22}$. A diferença entre a vontade humana e a vontade divina é que esta tem uma amplitude maior, dado que se estende a mais coisas e que Deus tem o entendimento de todas as ideias claras e distintas, que são a matéria que estimula a vontade. Em Deus, a vontade é criadora da verdade, por isso é mais ampla; no homem a vontade tem a função de descobrir a verdade, pois ela “[...] leva o entendimento a ver essas verdades." (TEIXEIRA, p. 57).

Relacionado ao tema da vontade, que Descartes também chama de livre arbítrio, está o tema da liberdade. Segundo o autor, a liberdade ${ }^{23}$ não consiste apenas na possibilidade de se inclinar aos prós ou contras de determinada ideia, mas em escolher o que é correto, em outras palavras, aquilo que é claro e distinto ${ }^{24}$. Cabe à vontade, não ao entendimento, inclinar-se a algo. A opção por uma ideia clara e distinta ainda é função do livre arbítrio. No entanto, Descartes acentua que a liberdade pode se apresentar em um grau menor, na medida em que a vontade se depara com uma ideia que contém em si não apenas elementos claros e distintos, mas também elementos confusos. Nesses casos, a vontade se depara com uma indiferença, uma falta de razão que impele a determinada opção. Como os dados em que a vontade atua são oferecidos pelo entendimento e a realidade deste são as ideias claras e distintas, Menezes aponta que a vontade se inclina para a verdade, dado que ela se identifica com a clareza e distinção das ideias. É nesse contexto que a autora nos fala de uma "orientação intrínseca da vontade em direção à verdade” (Id, 2011 p.132). Se, em alguns casos, há falta clareza e distinção na ideia, a vontade, pelo ato do juízo, pode se inclinar para aquilo que não é verdadeiro.

\footnotetext{
${ }^{21}$ Ver nota de número 62 em que o tradutor Gustavo de Fraga comenta esse trecho sobre a coisa pensante. (Cf. DESCARTES, 1988, p.124)

${ }^{22}$ Ibid, p.170-171.

${ }^{23}$ Vale notar que o tema da liberdade é amplo nos escritos de Descartes. Estudiosos apresentam a questão do sentido da liberdade, basicamente, sobre dois aspectos. A saber: uma liberdade que se funda na inclinação irresistível da vontade à verdade e uma liberdade que pode ser indiferente mesmo diante das ideias claras e distintas. Lívio Teixeira apresenta essa questão de modo bem contundente na seção intitulada Verdade $e$ Liberdade em seu Ensaio sobre a Moral em Descartes. (Cf.: TEIXEIRA, 1990, p.51-67)

${ }^{24}$ DESCARTES, 1988, p. 172.
} 
Então, visto que a vontade tem uma dimensão mais ampla em relação ao entendimento e que nem sempre as ideias que se encontram nele presentes são claras e distintas, Descartes situa o problema do erro nesse maior alcance da vontade em relação ao entendimento, pois ela não se restringe apenas às ideias claras e distintas deste ${ }^{25}$. Se alguém delibera sobre algo sem posse de ideias claras e distintas pode cair em erro de juízo. Nessa situação, erro se identifica com ignorância da verdade. Novamente recaímos no tema da indiferença ou falta de evidências que orientem a razão, retomando a tese de que o erro não possui uma realidade objetiva, mas é uma privação. E se o erro também não é real, Descartes garante, assim, a impossibilidade de se atribuir a Deus as causas do erro ${ }^{26}$.

O autor vai mais além quando afirma que podemos evitar o erro de um modo relativamente simples. Quando não possuímos ideias claras e distintas sobre alguma coisa não erramos na medida em que nos abstemos do juízo ${ }^{27}$. A suspensão do juízo, que foi utilizada nas primeiras meditações para se chegar à certeza do cogito, revela-se como um ato de prudência. A vontade, nesses casos, poderia ser orientada a não emitir juízos. Se, por um lado, é a vontade que se precipita e cai em erro, por outro lado, é a própria vontade que pode, livremente, determinar-se e se abster do juízo. O processo da dúvida levado ao seu extremo só é possível quando essa eleição é feita. Seja pela dúvida ou pelo juízo, a vontade está orientada para o conhecimento da verdade.

Descartes também expressa em seus escritos que é possível adquirir um hábito de não errar. Visto que não possuímos todas as ideias claras e distintas, podemos recorrer à nossa faculdade da memória. O uso da memória por uma meditação atenta é capaz de nos exercitar no método de não errar, pois os procedimentos de uma recordação atenta podem nos remeter às ideias claras e distintas antes apreendidas. E na medida em que nos habituamos a esse exercício, ele nos será mais acessível e produzirá em nós o hábito de não emitir juízo ao que não é seguro ao entendimento ${ }^{28}$.

No último parágrafo do texto da Quarta Meditação, Descartes retoma o conteúdo abordado ao longo da meditação, de modo a oferecer ao leitor uma síntese do assunto que foi abordado. Em acréscimo, o autor mostra que a sucessão dos argumentos culmina na expressão da verdade. Ele nos escreve sobre as causas do erro e dos modos de evitá-lo, e continua:

Todo o conceito claro e distinto é, sem dúvida, alguma coisa e, por

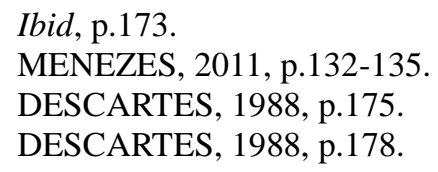


conseguinte, não pode ser a partir do nada, mas tem necessariamente Deus como autor, quero dizer, aquele Deus sumamente perfeito a que repugna ser enganador: e, logo, sem dúvida, é verdadeiro. Hoje não aprendi apenas o que devo evitar para que nunca me engane, mas também, simultaneamente, o que devo fazer para atingir a verdade. $(I d, 1988$, p.178-179)

Ao descobrir as causas do erro, o autor descobriu, também, um método para se chegar à verdade, ou seja, fixar-se na clareza e distinção das ideias. Daí também se segue a importância de Deus nesse processo de desvelamento da verdade, pois ele é a própria garantia da verdade. Vale também destacar que essa imagem de Deus apresentada por Descartes não é a mesma que a cristã, pois ela se baseia muito mais em um Princípio Causal de Necessidade do que nos dados cristãos da Revelação Divina. Contudo, uma não nega a outra.

A título de conclusão, vale resgatar a importância da vontade para a filosofia cartesiana. Desde o desenvolvimento de seu método à descrição do problema do erro e solução do mesmo, Descartes destaca a pertinência da vontade na vida humana. Ela, como elemento constitutivo da coisa pensante, é que abre as portas ao erro e à verdade. $\mathrm{O}$ objetivo das meditações cartesianas é alcançado pela resolução da vontade em encontrar a verdade. “Tanto mais que uma conquista da inteligência, a clareza das ideias é uma vitória da vontade." (TEIXEIRA, 1990, p.30). Por isso alguns estudiosos afirmam que há uma diferença de valor entre vontade e entendimento ${ }^{29}$. O erro encontra seu início e seu fim na vontade e na força que esta tem de se autodeterminar.

\section{BIBLIOGRAFIA}

DESCARTES, René. Les Principes de la Philosophie. Paris: Librairie Philosophique T. Vrin, 1970. 1988.

Meditações sobre a Filosofia Primeira. Tradução de Gustavo de Fraga. Coimbra:

ARIEW, Roger. Descartes e o escolasticismo: o pano de fundo intelectual do pensamento de Descartes. In: COTTINGHAM, John. [Org.] Descartes. Aparecida: Ideias \& Letras, 2009. p.78-114. (Coleção Companions \& Companions).

COTTINGHAM, John. A Filosofia de Descartes. Lisboa: Edições 70, 1989. p.13-38.

\footnotetext{
${ }^{29}$ Teixeira trabalha com essa ideia. Segundo ele, a independência da vontade em relação ao entendimento e a capacidade que ela tem de se autodeterminar mostra o quando elas estão em níveis diferenciados. Ver: TEIXEIRA, 1990, p.51-54.
} 
FORLIN, Enéias. O papel da dúvida metódica no processo de constituição do cogito. São Paulo: Associação Editorial Humanitas, 2004. p.17-58

LOYOLA, Inácio de. Exercícios Espirituais. 3.ed. São Paulo: Edições Loyola, 2006.

MENEZES, Ethel. Infinitude e Vontade nos Homens e em Deus segundo Descartes. In: Analytica (Revista de Filosofia), vol.15, n.1, 2011, p.125-144.

TEIXEIRA, Lívio. Ensaio sobre a Moral de Descartes. 2.ed. São Paulo: Editora Brasiliense, 1990. p.23-79. 